\title{
The In Vitro-In Vivo Safety Confirmation of PEG-40 Hydrogenated Castor Oil as a Surfactant for Oral Nanoemulsion Formulation
}

\author{
Heni Rachmawati ${ }^{1,2, *}$, Miranti Anggraeni Novel ${ }^{1}$, Sri Ayu ${ }^{1}$, Guntur Berlian ${ }^{3}$, \\ Olivia Mayasari Tandrasasmita ${ }^{3}$, Raymond Rubianto Tjandrawinata ${ }^{3}$ and \\ Kusnandar Anggadiredja ${ }^{1}$ \\ 1 School of Pharmacy, Institut Teknologi Bandung, Jalan Ganesha 10, 40132 Bandung, Indonesia; \\ anggraeninovel@gmail.com (M.A.N.); sriayu2097@gmail.com (S.A.); kusnandar@fa.itb.ac.id (K.A.) \\ 2 Research Center for Nanosciences and Nanotechnology, Institut Teknologi Bandung, Jalan Ganesha 10, \\ 40132 Bandung, Indonesia \\ 3 Dexa Laboratories of Biomolecular Sciences, Jababeka, Cikarang 17530, Indonesia; \\ guntur.berlian@dexa-medica.com (G.B.); olivia.tandrasasmita@dexa-medica.com (O.M.T.); \\ raytjan@yahoo.com (R.R.T.) \\ * Correspondence: h_rachmawati@fa.itb.ac.id
}

Academic Editor: Gernot Eller

Received: 22 December 2016; Accepted: 27 March 2017; Published: 31 March 2017

\begin{abstract}
Evaluation on the safety use of high concentration of polyoxyl 40 (PEG-40) hydrogenated castor oil as a surfactant for oral nanoemulsion was performed in Webster mice. As previously reported, nearly $20 \%$ of PEG-40 hydrogenated castor oil was used to emulsify the glyceryl monooleate (GMO) as an oil to the aqueous phase. Thermodynamically stable and spontaneous nanoemulsion was formed by the presence of co-surfactant polyethylene glycol 400 (PEG-400). Standard parameters were analyzed for nanoemulsion including particle size and particle size distribution, the surface charge of nanoemulsion, and morphology. To ensure the safety of this nanoemulsion, several cell lines were used for cytotoxicity study. In addition, $5000 \mathrm{mg} / \mathrm{kg}$ body weight (BW) of the blank nanoemulsion was given orally to Webster mice once a day for 14 days. Several parameters such as gross anatomy, body weight, and main organs histopathology were observed. In particular, by considering the in vivo data, it is suggested that nanoemulsion composed with a high amount of PEG-40 hydrogenated castor oil is acceptable for oral delivery of active compounds.
\end{abstract}

Keywords: PEG-40 hydrogenated castor oil; self-nanoemulsion; glyceryl monooleate; oral delivery; cytotoxicity

\section{Introduction}

Nanoemulsions consist of fine oil-in-water dispersions, having droplets covering the size range of 100-600 nm and thermodynamically stable. Stabilization is mostly due to the presence of a combination of surfactant and co-surfactant [1-5]. Nanoemulsion is successfully formed when a high concentration of surfactant is applied. In the formation of nanoemulsion, the free energy of formation is very low and positive or even negative, which results in thermodynamic spontaneous emulsification [6]. Self-emulsification happens due to the penetration of the aqueous phase into the liquid crystalline (LC) phase that is formed at the oil/surfactant-water interface into which water can penetrate, facilitated by gentle agitation during self-emulsification [1,3,4]. After water penetrates to a certain extent, there is a disruption of the interface and a droplet formation. This LC phase is considered to be responsible for the high stability of the resulted nanoemulsion against coalescence $[7,8]$. One consideration of developing nanoemulsion as potential drug carriers is applying 
a high concentration of surfactant. Non-ionic surfactants used for carrier formation and stabilizer include polyoxyl 35 castor oil (Cremophor EL), polysorbate 20 (Tween 20), polyoxyl 40 (PEG-40) hydrogenated castor oil, D- $\alpha$-tocopherol polyethylene glycol 1000 succinate (TPGS), polysorbate 80 (Tween 80), sorbitan monooleate (Span 80), polyoxyl 40 stearate, Solutol HS-15, and various polyglycolyzed glycerides including Labrasol, Gellucire 44/14, Labrafil M-1944CS, and Labrafil M-2125CS [6,9]. Previously, we had established nanoemulsion formulas using both Tween 20 and PEG-40 hydrogenated castor oil as surfactants for different applications of drug loading (curcumin, insulin, bovine serum albumin, recombinant human interferon $\alpha-2 b)$ [6,10-12].

This report describes a toxicity study of blank nanoemulsion using PEG-40 hydrogenated castor oil as a surfactant we applied in order to load various active compounds for oral administration. The aim was to confirm the safety of using high concentrations ( 20\%) of PEG-40 hydrogenated castor oil in the formula, especially when used long-term. Polyoxyl 40 hydrogenated castor oil is a non-ionic solubilizer and emulsifying agent that is obtained by reacting hydrogenated castor oil with ethylene oxide [13]. The main constituent of this product is glyceryl polyethylene glycol oxystearate. Together with fatty acid glyceryl polyglyceryl esters, they form the hydrophobic part of the product.

An acute toxicity test of blank nanoemulsion as our universal drug carrier was carried out in mice. Nanoemulsion was given orally at a single dose of $5000 \mathrm{mg} / \mathrm{kg}$ body weight ( 5 males, 5 females). Observation was performed for 14 days after the administration, and the parameters studied include behavioral changes, mortality or differences in gross anatomy of internal organs, organ indices, and histological analysis.

\section{Materials and Methods}

\subsection{Materials}

Glyceryl monooleate (GMO) was purchased from PT. Tritunggal (Jakarta, Indonesia). Polyoxyl 40 hydrogenated castor oil was purchased from BASF (Ludwigshafen, Germany). Polyethylene glycol 400 (PEG-400) was commercially provided by PT. Bratachem (Bandung, Indonesia). Dulbecco's Modified Eagle Medium (DMEM), Eagle's Minimum Essential Medium (EMEM), the Roswell Park Memorial Institute (RPMI) 1640 medium, penicillin-streptomycin, bovine serum, fetal bovine serum, and trypsin-ethylenediaminetetraacetic acid (EDTA) were purchased from Gibco (Waltham, MA, USA). 3-(4,5-Dimethylthiazol-2-yl)-5-(3-carboxymethoxyphenyl)-2-(4-sulfophenyl)-2H-tetrazolium (MTS) reagents were purchased from Promega (Madison, WI, USA).

\subsection{Cell Line}

NIH/3T3 (mouse fibroblast cell line, CRL-1658), 3T3-SA (Swiss albino mouse fibroblast cell line, CCL-92), RSC-96 (rat neuron Schwann cell line, CRL-2765), RAW 264.7 (mouse macrophage cell line, TIB-71), RBL-2H3 (rat basophilic leukemia cell line, CRL-2256), CHO-K1 (Chinese hamster ovary cell line, CCL-61), NCI-H292 (human tumor cell line, CRL-1848), and Caco-2 (human epithelial colorectal adenocarcinoma cell) were purchased from American Type Culture Collection (ATCC) (Rockville, MD, USA).

\subsection{Animal}

Specific, pathogen-free male and female Webster mice weighing 25-30 $\mathrm{g}$ at the beginning of experiment were used. Animal were obtained from School of Pharmacy, Bandung Institute of Technology, Indonesia. The mice received a standard diet and were housed under standard laboratory conditions. The study as presented was approved by the Local Committee for Care and Use of Laboratory Animals, School of Pharmacy, Bandung Institute of Technology, Indonesia (Certificate No. 08/KEPHP-ITB/032015) and was performed according to strict governmental and international guidelines on animal experimentation. 


\subsection{Preparation of Blank Nanoemulsion}

Blank nanoemulsion consisted of an oil phase of GMO, PEG-40 hydrogenated castor oil and PEG-400 (1:8:1) was prepared using our established formula [6]. The mixture of oil, surfactant and co-surfactant were stirred at $100 \mathrm{rpm}$ for $2 \mathrm{~h}$. Further sonication for $1 \mathrm{~h}$ using a bath sonicator (Nagoya S Ultrasonic Cleaner GB-928, Shenzhen Co.Ltd, Guangdong, China) was applied to complete the mixing process. To obtain nanoemulsion, deionized water was added to the oil phase at a ratio of 5:1 and stirred gently. Blank nanoemulsion was spontaneously formed after this protocol.

\subsection{Physical Characterization of Blank Nanoemulsion}

Characterization of blank nanoemulsion was performed as previously [6]. Briefly, the successful formation of nanoemulsion was evaluated based on analysis of particle size and particle size distribution, and zeta potential using particle size analyzer (Delsa Nano C Particle Analyzer, Beckman Coulter, Brea, CA, USA).

Particle morphology of the nanoemulsion was analyzed by transmission electron microscopy (TEM) using a JEM-1400 transmission electron microscope (JEOL, Tokyo, Japan). About $10 \mathrm{~mL}$ of sample was dropped in the specimen place and covered with a 400 mesh grid. After $1 \mathrm{~min}, 10 \mathrm{~mL}$ of uranyl acetate was dropped on top of the grid, and this sample was allowed to dry for 30 min before observation under the transmission electron microscope. This procedure was used to confirm the particle size in the nanoemulsion as measured using the particle size analyzer.

\subsection{Stability Study of Blank Nanoemulsion in Gastrointestinal Tract Simulation Fluids}

The proposed delivery system of this nanoemulsion is for oral route. In order to ensure the physical stability of the nanoemulsion, the influence of gastrointestinal tract (GIT) condition was evaluated using both gastric simulation fluid $(0.1 \mathrm{~N} \mathrm{HCl})$ and intestinal simulation fluid (phosphate buffer at $\mathrm{pH}$ 6.8) at $37^{\circ} \mathrm{C}$ for $3 \mathrm{~h}$, respectively. Same volume ratio of nanoemulsion and GIT simulation fluid was mixed and observation was done visually and by measuring the particle size as previously described.

\subsection{Stability Study of Blank Nanoemulsion during Storage}

The physical stability of the blank nanoemulsion was performed by storing the sample at room temperature for nine months. The observation was done visually and by measuring the particle size as previously described.

\subsection{In Vitro Cytotoxicity Assay}

Cytotoxic effect of blank nanoemulsion on several cell lines including NIH/3T3, 3T3-SA, RSC-96, RAW 264.7, RBL-2H3, CHO-K1, Caco-2, and NCI-H292 was determined using MTS assay according to the manufacturer's protocol (Promega). Briefly, cells were trypsinized and plated into 96-well plate at density of $10^{4}$ cells/well. Cells were cultured overnight at $37^{\circ} \mathrm{C}$ with $5 \% \mathrm{CO}_{2}$. Cells were added with $20 \mathrm{mg} / \mathrm{mL}$ of blank nanoemulsion. Further, cells were incubated overnight and immediately added with $20 \mu \mathrm{L}$ of MTS to each well. The cells were reincubated for $2 \mathrm{~h}$ at $37^{\circ} \mathrm{C}$ with $5 \% \mathrm{CO}_{2}$. The absorbance was measured at $490 \mathrm{~nm}$ using enzyme-linked immunosorbent assay (ELISA) microplate reader (Biorad, Hercules, CA, USA). The result was represented as percentage of cell viability, compared to untreated controls.

\subsection{Acute Toxicity Study}

Experimental procedures were carried out according to the World Health Organization (WHO) guidelines [14] and that of the Organization for Economic Co-operation and Development (OECD) for testing of chemicals, TG240 [15]. Five male and five female mice were given a single dose of $5000 \mathrm{mg} / \mathrm{kg}$ of the test substance. All mice were observed for toxicity signs, beharioral changes and mortality $30 \mathrm{~min}, 1$, 2, 4, and $24 \mathrm{~h}$ after the administration. Similar observations were also performed 
once daily for 14 days. On day 15, all mice were fasted for $18 \mathrm{~h}$ and then sacrificed for gross anatomical examination of main internal organs. The organs were weighed, and observed macroscopically and microscopically. The microscopic observation was done through a standard histopatological examination using hematoxylin-eosin (HE) staining according to a standard protocol for HE staining on $5 \mu \mathrm{M}$ of paraffin-embedded tissues [16,17].

\subsection{Statistical Analysis}

Statistical analysis was performed using one-way analysis of variance (ANOVA) for parametric data followed by post hoc method, and Mann-Whitney analysis for non-parametric data. A $p$-value $<0.05$ was considered statistically significant.

\section{Results and Discussion}

Various processes take place during emulsification, including breakup of the droplets, adsorption of surfactant molecules, and droplets collision. These processes may occur simultaneously. Breaking of drops is feasible if the deforming force exceeds the Laplace pressure $\left(P_{L}\right)$, which is the interfacial force that acts against droplet deformation:

$$
P_{L}=\gamma\left(1 / R_{1}+1 / R_{2}\right)
$$

$R_{1}$ and $R_{2}$ are the smaller and the larger radii of the curvature of a deformed emulsion drop respectively, and $\gamma$ is the interfacial force. Based on the Laplace equation [18], the droplet size is reduced with decreasing oil/surfactant ratio (increasing surfactant concentration). To form spontaneous nanoemulsion, not only is a high concentration of surfactant required, but so also is surfactant with a high HLB (hydrophilic and lipophilic balance) of over 12 [7]. Polyoxyl 40 hydrogenated castor oil used in this study shows a high HLB of between 14 and 16. Although non-ionic surfactant like PEG-40 hydrogenated castor oil is safer than ionic surfactant, applying a higher concentration in oral dosage form or via other routes of administration must be ensured, especially for a longer period of time, as reported here.

\subsection{Physical Characteristics of Blank Nanoemulsion}

The nanoemulsion produced a transparent dispersion due to smaller oil droplets, dispersed in the aqueous phase as confirmed by particle size measurement (Table 1) and microscopic observation (Figure 1).

Table 1. Physical parameters of blank nanoemulsion.

\begin{tabular}{cc}
\hline Parameters & Value * $^{*}$ \\
\hline Particle size $(\mathrm{nm})$ & $21.4 \pm 5.8$ \\
Polydispersity Index & $0.245 \pm 0.177$ \\
Zeta $(\zeta)$ potential $(\mathrm{mV})$ & $-10.6 \pm 1.12$ \\
\hline * Each parameter was determined in triplicates.
\end{tabular}

As clearly seen in Figure 1, the nanoemulsion showed a polydispersion system where most globules were at a size of $<25 \mathrm{~nm}$. The larger droplets of $>25 \mathrm{~nm}$ are suggestive of smaller droplet coalescence. However, this phenomenon was controlled as confirmed by the transparent appearance of the nanoemulsion after a long storage period (nine months) at room temperature (Figure 2). 


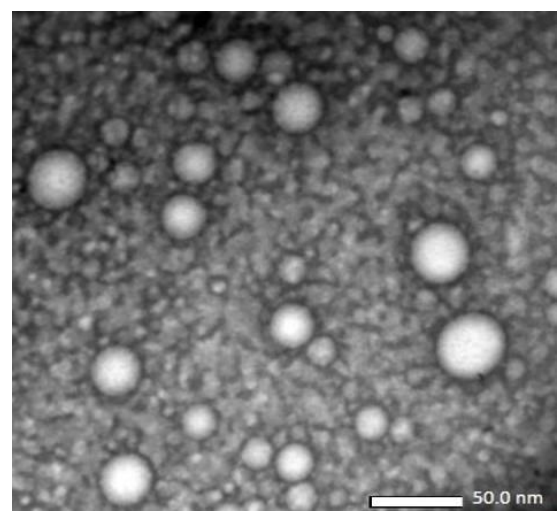

Figure 1. Cryo-transmission electron microscopic (cryo-TEM) observation of blank nanoemulsion $(10,000 \times$ magnification).

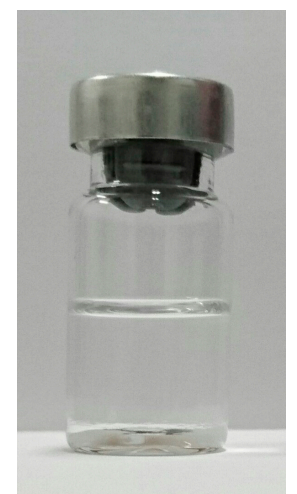

(A)

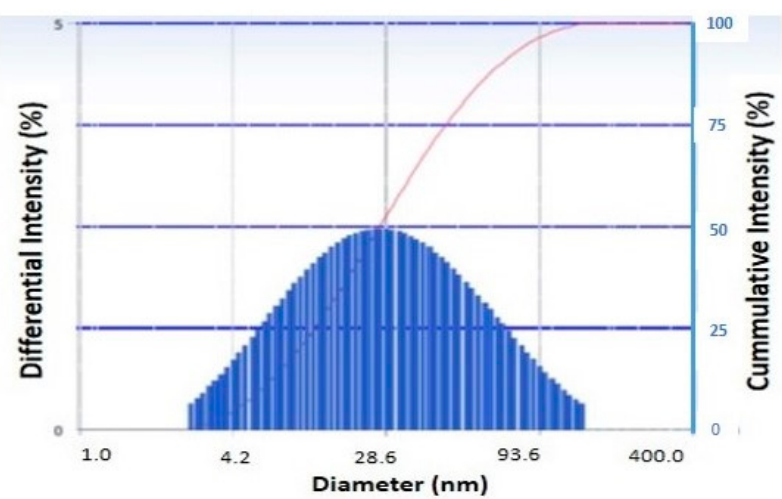

(B)

Figure 2. Visual appearance (A) and globule size distribution (B) of blank nanoemulsion after nine months storage at room temperature.

The negatively charged particle surface of the colloidal system (Table 1) is represented by the PEG-40 hydrogenated castor oil molecules covering the oil droplet surface. The negative charge was likely the result of the various hydrophilic groups of the non-ionic surfactant. The adsorption of non-ionic surfactant preferentially influences hydroxyl ions $\left(\mathrm{OH}^{-}\right)$on the surface of a droplet and therefore alters the zeta $(\zeta)$ potential of the droplet.

As presented in Figure 3, the nanoemulsion (a globule diameter of $20.9 \mathrm{~nm}$, polydispersity index (PI, 0.394) is resistance to the GIT fluids. The nanoemulsion remained clear after incubation with either $0.1 \mathrm{~N} \mathrm{HCl}$ (globule diameter of $19.6 \mathrm{~nm}$, PI 0.084) or phosphate buffer $\mathrm{pH} 6.8$ (globule diameter of 21.7 $\mathrm{nm}, \mathrm{PI} 0.447$ ) at $37^{\circ} \mathrm{C}$ for 2 and $4 \mathrm{~h}$, respectively. This indicated that no extensive coalescence occurred, which was confirmed by particle size analysis (PSA) data.

The stable dispersion system formed by this established formula was also shown (Figure 3) when the nanoemulsion was kept at room temperature for nine months. Likewise, no extensive coalescence was detected indicated by the transparency of the preparation, which was also confirmed by PSA data (globule diameter of $25.1 \mathrm{~nm}$, PI 0.079). 


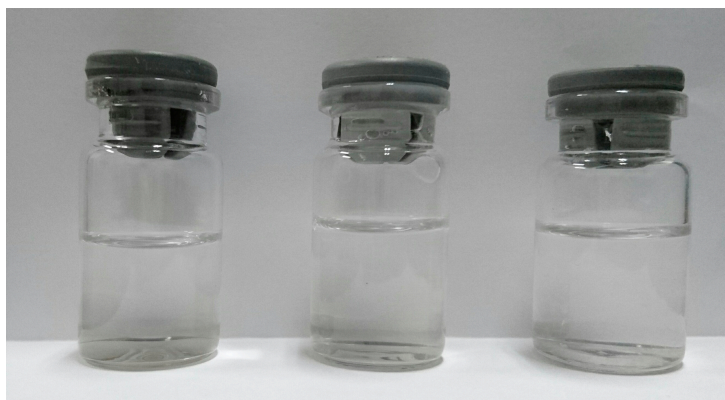

(A)
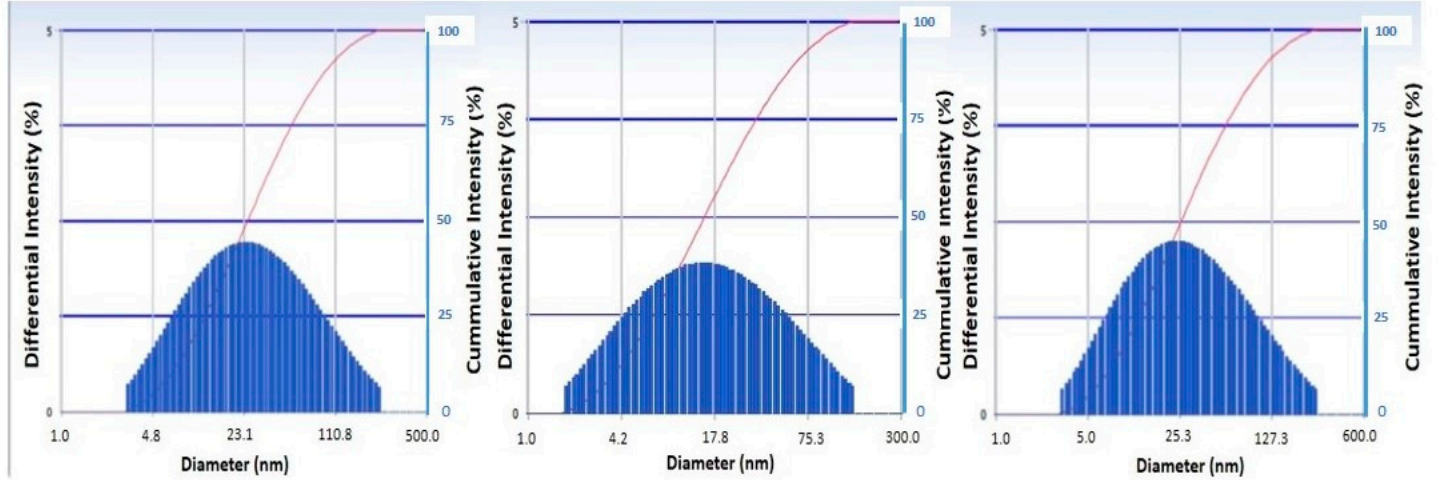

(B)

Figure 3. Visual appearance (A) and the globule size distribution (B) of blank nanoemulsion (left), blank nanoemulsion after being incubated with $0.1 \mathrm{~N} \mathrm{HCl} \mathrm{1:1} v / v$ (middle), and blank nanoemulsion after incubated with phosphate buffer ( $\mathrm{pH}$ 6.8) 1:1 v/v (right). The incubation was done at $37^{\circ} \mathrm{C}$.

\subsection{Cytotoxicity Assay}

Figure 4 presents cytotoxicity data in different cell lines. Blank nanoemulsion did not demonstrate any cytotoxic effect on NIH/3T3, 3T3-SA, RSC-96, RAW 264.7, RBL-2H3, CHO-K1, NCI-H292, and Caco-2 cell lines.

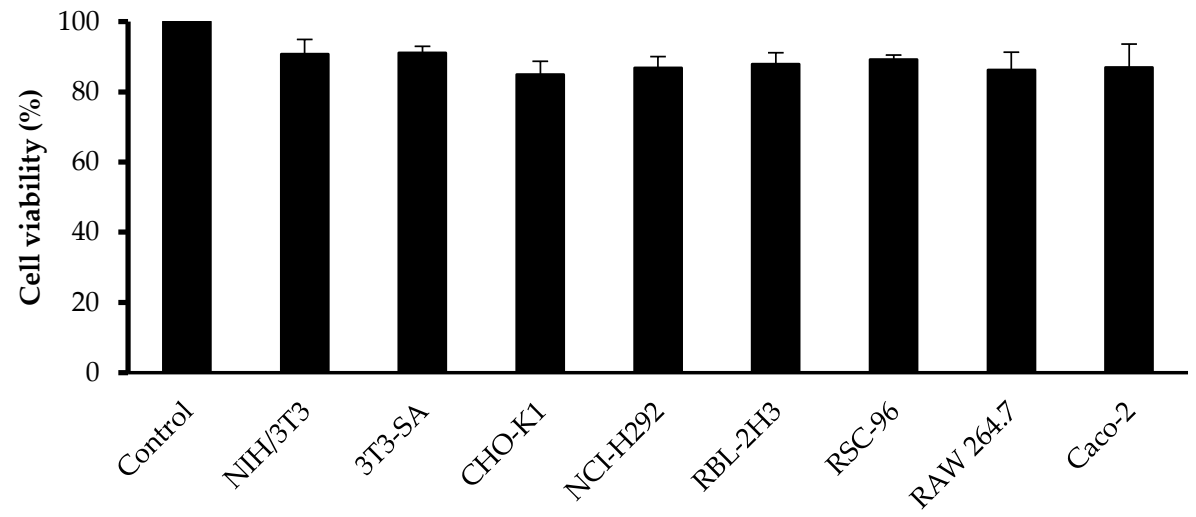

Figure 4. Cytotoxic effect on different cell lines.

\subsection{Acute Toxicity Analysis}

The result of behavioral assessment is presented in Table 2. Following administration of as high as $5000 \mathrm{mg} / \mathrm{kg}$ of the test substance, neither abnormal behavioral changes nor death were observed during the entire $24 \mathrm{~h}$ obervation period. Thus, the lethal dose 50 (LD50) could not be observed at the dose used in the experiment. 
Table 2. Effects of the test substance on behavior following its single-high dose administration. A single dose of $5000 \mathrm{mg} / \mathrm{kg}$ was given to five mice of both sexes, followed by behavioral examination during a $24 \mathrm{~h}$ observation period.

\begin{tabular}{|c|c|c|c|c|c|c|c|c|c|c|c|c|c|c|}
\hline & & & \multicolumn{12}{|c|}{ Observation Period (h) } \\
\hline \multicolumn{3}{|c|}{ Parameter } & \multicolumn{6}{|c|}{ Male } & \multicolumn{6}{|c|}{ Female } \\
\hline & & & 0 & 0.5 & 1 & 2 & 4 & 24 & 0 & 0.5 & 1 & 2 & 4 & 24 \\
\hline Platf & orm & $*)$ & 3.8 & 4.2 & 3.4 & 2.2 & 1.8 & 3.8 & 8.8 & 6.4 & 4.6 & 4.0 & 4.0 & 11.0 \\
\hline \multirow{4}{*}{$\begin{array}{l}\text { Motor } \\
\text { Activity }\end{array}$} & Inrease & $(\%)$ & 0 & 0 & 0 & 0 & 0 & 0 & 0 & 0 & 0 & 0 & 0 & 0 \\
\hline & Normal & $(\%)$ & 100 & 100 & 100 & 100 & 100 & 100 & 100 & 100 & 100 & 100 & 100 & 100 \\
\hline & Descrease & $(\%)$ & 0 & 0 & 0 & 0 & 0 & 0 & 0 & 0 & 0 & 0 & 0 & 0 \\
\hline & Immobile & $(\%)$ & 0 & 0 & 0 & 0 & 0 & 0 & 0 & 0 & 0 & 0 & 0 & 0 \\
\hline \multicolumn{2}{|c|}{ Straub } & $(\%)$ & 0 & 0 & 0 & 0 & 0 & 0 & 0 & 0 & 0 & 0 & 0 & 0 \\
\hline \multicolumn{2}{|c|}{ Piloerection } & $(\%)$ & 0 & 0 & 0 & 0 & 0 & 0 & 0 & 0 & 0 & 0 & 0 & 0 \\
\hline \multicolumn{2}{|c|}{ Ptosis } & $(\%)$ & 0 & 0 & 0 & 0 & 0 & 0 & 0 & 0 & 0 & 0 & 0 & 0 \\
\hline \multicolumn{2}{|c|}{ Pineal reflex } & $(\%)$ & 100 & 100 & 100 & 100 & 100 & 100 & 100 & 100 & 100 & 100 & 100 & 100 \\
\hline \multicolumn{2}{|c|}{ Corneal reflex } & $(\%)$ & 100 & 100 & 100 & 100 & 100 & 100 & 100 & 100 & 100 & 100 & 100 & 100 \\
\hline \multicolumn{2}{|c|}{ Lacrimation } & $(\%)$ & 0 & 0 & 0 & 0 & 0 & 0 & 0 & 0 & 0 & 0 & 0 & 0 \\
\hline \multicolumn{2}{|c|}{ Catalepsy } & $(\%)$ & 0 & 0 & 0 & 0 & 0 & 0 & 0 & 0 & 0 & 0 & 0 & 0 \\
\hline \multirow{2}{*}{ Gait } & Normal & $(\%)$ & 100 & 100 & 100 & 100 & 100 & 100 & 100 & 100 & 100 & 100 & 100 & 100 \\
\hline & Abnormal & $(\%)$ & 0 & 0 & 0 & 0 & 0 & 0 & 0 & 0 & 0 & 0 & 0 & 0 \\
\hline \multicolumn{2}{|c|}{ Front leg suspension } & $(\%)$ & 100 & 100 & 100 & 100 & 100 & 100 & 100 & 100 & 100 & 100 & 100 & 100 \\
\hline \multicolumn{2}{|c|}{ Establishment } & $(\%)$ & 100 & 100 & 100 & 100 & 80 & 100 & 100 & 100 & 100 & 100 & 100 & 100 \\
\hline \multicolumn{2}{|c|}{ Flexion } & $(\%)$ & 100 & 100 & 100 & 100 & 100 & 100 & 100 & 100 & 100 & 100 & 100 & 100 \\
\hline \multicolumn{2}{|c|}{ Hafner reflex } & $(\%)$ & 100 & 100 & 100 & 100 & 100 & 100 & 100 & 100 & 100 & 100 & 100 & 100 \\
\hline \multicolumn{2}{|c|}{ Mortality } & $(\%)$ & 0 & 0 & 0 & 0 & 0 & 0 & 0 & 0 & 0 & 0 & 0 & 0 \\
\hline \multicolumn{2}{|c|}{ Grooming } & $(\%)$ & 20 & 20 & 0 & 0 & 20 & 60 & 20 & 60 & 40 & 40 & 0 & 40 \\
\hline \multicolumn{2}{|c|}{ Defecation } & $(\%)$ & 40 & 20 & 40 & 40 & 60 & 20 & 100 & 80 & 60 & 20 & 60 & 100 \\
\hline \multicolumn{2}{|c|}{ Urination } & $(\%)$ & 40 & 20 & 40 & 40 & 60 & 40 & 60 & 60 & 20 & 20 & 20 & 40 \\
\hline \multirow{3}{*}{ Respiration } & Rapid & $(\%)$ & 0 & 0 & 0 & 0 & 0 & 0 & 0 & 0 & 0 & 0 & 0 & 0 \\
\hline & Normal & $(\%)$ & 100 & 100 & 100 & 100 & 100 & 100 & 100 & 100 & 100 & 100 & 100 & 100 \\
\hline & Short & $(\%)$ & 0 & 0 & 0 & 0 & 0 & 0 & 0 & 0 & 0 & 0 & 0 & 0 \\
\hline \multicolumn{2}{|c|}{ Salivation } & $(\%)$ & 0 & 0 & 0 & 0 & 0 & 0 & 0 & 0 & 0 & 0 & 0 & 0 \\
\hline \multicolumn{2}{|c|}{ Vocalization } & $(\%)$ & 0 & 0 & 0 & 0 & 0 & 0 & 0 & 0 & 0 & 0 & 0 & 0 \\
\hline \multicolumn{2}{|c|}{ Tremor } & $(\%)$ & 0 & 0 & 0 & 0 & 0 & 0 & 0 & 0 & 0 & 0 & 0 & 0 \\
\hline Conve & lltion & $(\%)$ & 0 & 0 & 0 & 0 & 0 & 0 & 0 & 0 & 0 & 0 & 0 & 0 \\
\hline Writ & ing & $(\%)$ & 0 & 0 & 0 & 0 & 0 & 0 & 0 & 0 & 0 & 0 & 0 & 0 \\
\hline
\end{tabular}

$\left.{ }^{*}\right)$ The average number of head dipping; \% = Percent of number of animals.

There were no signs of straub, piloerection, ptosis, catalepsy, lacrimation, vocalization, salivation, tremor, convulsions, or writhing observed in the first $24 \mathrm{~h}$ after the administration of the test substance. This demonstrates that the test substance did not cause toxic effect on the central nervous system. Motor activity as well as body posture, respiration, urination, and defecation were normal. Furthermore, all mice showed normal reflexes, which indicates that the test substance did not affect spinal integrity in the central nervous system.

Figure 5 shows that, during the 14-day observation period following the administration of the test substance, the body weight of the test mice fluctuated within a normal range, and no marked decrease in body weight could be found. This finding shows that in general the test substance did not produce hazardous effects, and it had no effect on food intake. This is based on observation and is not significantly different when both genders are compared $(p>0.05)$.

As shown in Figure 6, the organ-to-body weight ratios of all internal organs examined were within a normal range. A minor significant difference was observed in the liver, but this was not followed by other studied parameters, including HE histological analysis. The histological examination was performed to evaluate organ damage upon treatment with a compound [19]. With regard to the 
histological profile of the main organs, as depicted in Figure 7, the results showed that there was no deviation from normal in all organs of test substance-treated mice $(p>0.5)$, which further corroborates the safety of the test substance.

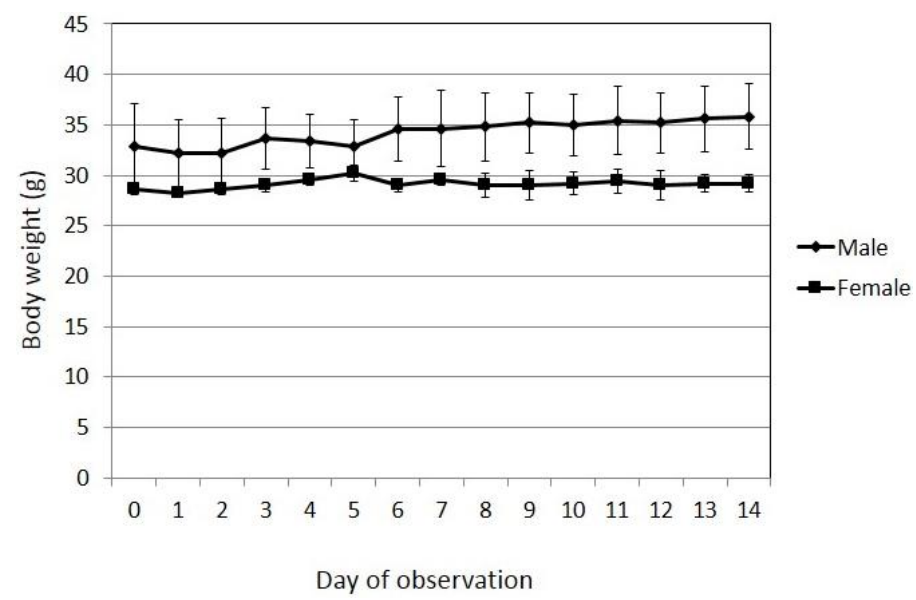

Figure 5. Fluctuation in the body weight of the test mice.

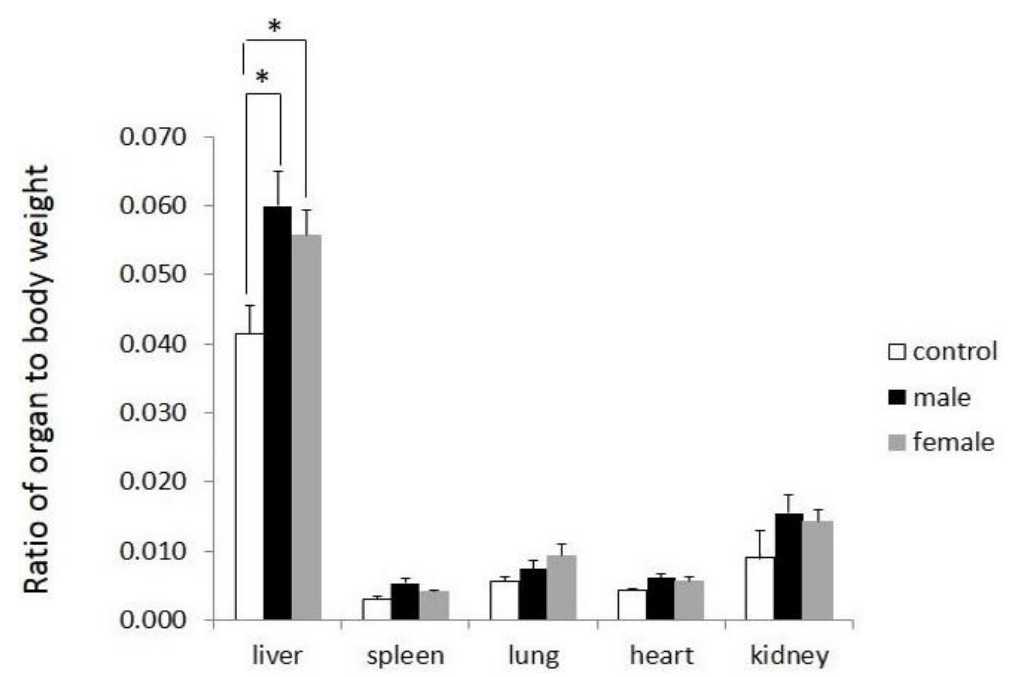

Figure 6. The organ-to-body weight ratios of the internal organs.

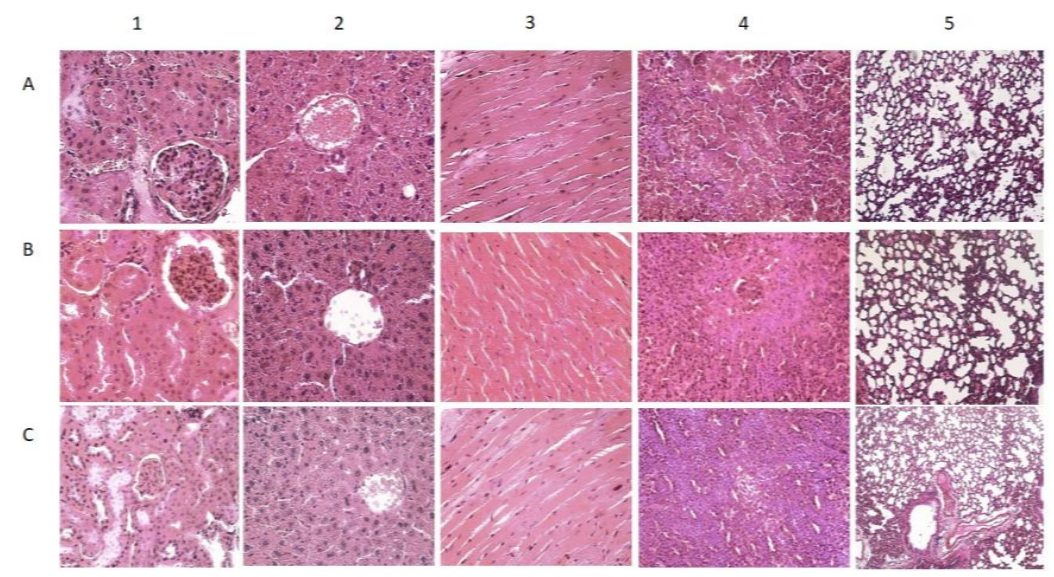

Figure 7. Histological results of the main organs-kidney (1), liver (2), heart (3), spleen (4), and lung (5) - from control (A), male (B) and female (C) mice receiving nanoemulsion. Magnification $100 \times$. 


\section{Conclusions}

Nanoemulsion composed with the component of an oil phase of GMO, PEG-40 hydrogenated castor oil as a surfactant, and PEG 400 as a co-surfactant (1:8:1) does not show any negative response when incubated in different types of cell lines. This in vitro data is confirmed in vivo after daily single-dose oral administration for 14 days. The use of high concentration of PEG-40 hydrogenated castor oil to form clear spontaneous and stable oil droplets when challenged in the GIT simulation fluids seems to be acceptable for the oral delivery of such active compounds loaded in the developed nanoemulsion.

Acknowledgments: This project was financially supported by Bandung Institute of Technology Research Grant, 2014.

Author Contributions: H.R. wrote the manuscript, designed the formulation of the nanoemulsion and its characterization, and supervised the entire project. M.A.N. and G.B. performed the in vitro experiment. S.A. performed stability test of the nanoemulsion. O.M.T. co-supervised and designed the in vitro work. R.T. approved and supervised the in vitro experiment. K.A. wrote the manuscript of animal experimentation, and designed and supervised the in vivo experiment.

Conflicts of Interest: The authors declare no conflict of interest.

\section{References}

1. Lawrence, M.; Rees, G. Microemulsion-based media as novel drug delivery systems. Adv. Drug Deliv. Rev. 2000, 45, 89-121. [CrossRef]

2. Reiss, H. Entropy-induced dispersion of bulk liquids. J. Colloid Interface Sci. 1975, 53, 61-70. [CrossRef]

3. Izquierdo, P.; Feng, J.; Esquena, J.; Tadros, J.F.; Dederen, J.C.; Garcia, M.J.; Azemar, N.; Solans, C. The influence of surfactant mixing ratio on nano-emulsion formation by the pit method. J. Colloid Interface Sci. 2005, 285, 388-394. [CrossRef] [PubMed]

4. Izquierdo, P.; Esquena, J.; Tadros, T.F.; Dederen, J.C.; Feng, J.; Garcia-Celma, M.J.; Azemar, N.; Solans, C. Phase behavior and nano-emulsion formation by the phase inversion temperature method. Langmuir 2004, 20, 6594-6598. [CrossRef] [PubMed]

5. Sing, A.J.F.; Gracia, A.; Lachaise, J.; Brochette, P.; Salager, J.L. Interactions and coalescence of nanodroplets in translucent O/W emulsions. Colloids Surf. A 1999, 152, 31-39. [CrossRef]

6. Rachmawati, H.; Budiputra, D.K.; Mauludin, R. Curcumin nanoemulsion for transdermal application: Formulation and evaluation. Drug Dev. Ind. Pharm. 2015, 41, 560-566. [CrossRef] [PubMed]

7. Groves, M.J.; Gallindez, D.A. The self-emulsifying action of mixed surfactants in oil. Acta Pharm. Suec. 1976, 13, 361-372. [PubMed]

8. Wakerly, M.; Pouton, C.; Meakin, B.; Morton, F. Self-emulsification of vegetable oil-nonionic surfactant mixtures. ACS Symp. Ser. 1986, 311, 242-255.

9. Thakkar, H.P.; Khunt, A.; Dhande, R.D.; Patel, A.A. Formulation and evaluation of Itraconazole nanoemulsion for enhanced oral bioavailability. J. Microencapsul. 2015, 32, 559-569. [CrossRef] [PubMed]

10. Rachmawati, H.; Haryadi, B.M.; Anggadiredja, K.; Suendo, V. Intraoral film containing insulin-phospholipid microemulsion: Formulation and in vivo hypoglycemic activity study. Am. Assoc. Pharm. Sci. PharmSciTech 2015, 16, 692-703. [CrossRef] [PubMed]

11. Rachmawati, H.; Haryadi, B.M. The influence of polymer structure on the physical characteristic of intraoral film containing BSA-loaded nanoemulsion. J. Nanomed. Nanotechnol. 2014, 5, 1-6.

12. Rachmawati, H.; Herawati, D.; Susilo, R.A.; Darijanto, S.T.; Sumirtapura, Y.C. The influence of oils and surfactants on the formation of self Nanoemulsifying Drug Delivery System (SNEDDS) containing therapeutic protein. Proc. Int. Conf. Mater. Sci. Technol. 2011, 247, 3-9.

13. Strickley, R. Solubilizing excipients in oral and injectable formulations. Pharm. Res. 2004, 21, $201-230$. [CrossRef] [PubMed]

14. World Health Organization (WHO). General Guidelines for Methodologies on Research and Evaluation of Traditional Medicine; World Health Organization: Geneva, Switzerland, 2000. 
15. The Organization of Economic Co-operation and Development (OECD). The OECD Guideline for Testing of Chemical: 420 Acute Oral Toxicity; The Organization of Economic Co-operation and Development: Paris, France, 2001.

16. Kiernan, J.A. Histological and Histochemical Methods: Theory and Practice, 4th ed.; Cold Spring Harbor Laboratory Press: Bloxham, UK, 2008.

17. Lillie, R.D.; Pizzolato, P.; Donaldson, P.T. Nuclear stains with soluble metachrome mordant lake dyes. The effect of chemical endgroup blocking reactions and the artificial introduction of acid groups into tissues. Histochemistry 1976, 49, 23-35. [CrossRef] [PubMed]

18. Butt, H.J.; Graf, K.; Kappl, M. Physics and Chemistry of Interfaces; Wiley: Hoboken, NJ, USA, 2006.

19. Singh, S.; Wasson, S. Drug toxicity research trends. In Drug Toxicity: New Research; Vellotis, C.E., Ed.; Nova Science Publishers Inc.: New York, NY, USA, 2008; pp. 11-12.

(C) 2017 by the authors. Licensee MDPI, Basel, Switzerland. This article is an open access article distributed under the terms and conditions of the Creative Commons Attribution (CC BY) license (http:/ / creativecommons.org/licenses/by/4.0/). 